\title{
Informes
}

\section{Próxima publicación de El Colegio de la Frontera Norte}

Próximamente El Colegio de la Frontera Norte (Colef) iniciará la publicación de Frontera Norte, una revista semestral de carácter académico, que incluirá artículos y ensayos en los cuales se aborden problemas y asuntos fronterizos, desde la perspectiva de las distintas ciencias. Al frente de esta nueva publicación está Jorge Carrillo.

Frontera Norte seré, por una parte, un foro en donde los investigadores de El Colef podrán presentar avances o resultados de su trabajo. $\mathrm{Al}$ mismo tiempo, servirá como puente de comunicación e integración entre los investigadores de El Colef residentes en Tijuana y los que trabajan en las distintas oficinas coordinadoras a lo largo de la frontera México-Estados Unidos. Por otra parte, será un vínculo más con la comunidad académica en ambos países. Los artículos publicados serán, fundamentalmente, resultado de investigaciones de carácter empírico (producto de una encuesta, por ejemplo), metodológico, o teórico. En general, puede decirse que se incluirán dos tipos de artículos (no necesariamente excluyentes): reflexivos e informativos.

Los trabajos publicados en Frontera Norte serán originales; sólo en casos excepcionales se incluirán trabajos ya publicados en revistas o compilaciones. La revista será bilingüe y los trabajos se publicarán en inglés o español, según hayan sido escritos originalmente. En el caso de artículos escritos.en algún otro idioma, se publicará una traducción al español. Cada artículo incluirá un resumen en el idioma que haya sido escrito originalmente.

Los académicos interesados en colaborar en este nuevo proyecto editorial pueden solicitar mayores informes sobre los requisitos para la publicación de textos, o enviar sus trabajos a las siguientes direcciones:

Jorge Carrillo

Re vista Frontera Norte

Blvd. Abelardo L. Rodríguez núm. 21

Zo na del Río

22320 Tijuana, B.C.

P.O.Box L

92012 Chula Vista, CA.

U.S.A. 